\title{
Electrochemical migration of Ni and ENIG surface finish during Environmental test contaminated by $\mathrm{NaCl}$
}

\author{
Bálint Medgyes \\ Department of Electronics Technology, Budapest University of Technology and Economics, \\ Egry József street 18., Building V1, Ground floor, Budapest H-1111, Hungary, \\ medgyes@ett.bme.hu
}

Abstract: The electrochemical migration (ECM) mechanism occurs at the presence of moisture in the case of operating circuits and results in shorts (dendrites) between adjacent conductor lines/traces. Dendrite growth occurs as a result of metal ions being dissolved into a solution from the anode and deposited at the cathode, thereby growing in tree-like formations. In this study the water condensation process and ECM behavior of Nickel (Ni), Electroless Nickel Immersion Gold (ENIG) and pure copper were investigated using Thermal Humidity and Bias (THB) test in $\mathrm{NaCl}$ environment. The THB results show that $\mathrm{Cu}$ has higher ECM resistance than Ni and ENIG surface finishes, which was an unexpected result. The main influencing factors of the water condensation (e.g.: surface roughness, thermal parameters) and the ECM processes (precipitates and dendrites) were investigated and discussed in details. Furthermore, a novel ECM model for $\mathrm{Ni}$ and NiAu surface finish was established using THB test in case $\mathrm{NaCl}$ contaminated samples.

Keywords: Electrochemical migration; Electroless Nickel Immersion Gold; Thermal Humidity and Bias test.

\section{Introduction}

The different humidity induced failure phenomena [1, 2] have even growing importance because of the high integration and miniaturization trends in the electronics. One of these failure phenomena is called electrochemical migration (ECM) [3, 4]. The first theoretical explanation of the ECM was given in connection with the silver migration [5]. In this classical migration model, dendrites are grown on the cathode by the deposition of anodically dissolved ionic constituents that are present in the conductive strips. The migrated resistive shorts occur at practically random locations, and emerge mainly under extreme conditions (i.e. elevated temperature and humidity). However, a number of electrical fieldgoverned failure types are correlated with migration. A device can operate for many hundreds of hours under normal operating conditions, and then, after a short exposure to special environmental conditions, it may fail suddenly [5]. Later it was proven in numerous further 
studies that several other metals also show dendrite growth caused by $\mathrm{ECM}$, i.e. $\mathrm{Cu}, \mathrm{Pb}, \mathrm{Sn}$, $\mathrm{Ni}$ and $\mathrm{Au}$.

Usually, the investigations are carried out in two different scenarios: one of them is done under laboratory circumstances (at room temperature and humidity), while the other one is carried out in extreme climatic conditions. The latter one is carried out by environmental tests, which provide high temperature and humidity levels, while the patterns are followed by some kinds of electrical parameters, such as surface insulation resistance, leakage current or voltage changing. However, the environmental tests provide data mainly about the ECM processes (fault detection) and give very little useful information about the antecedent processes such as water condensation mechanism. Although environmental tests can also simulate the mechanism of water condensation, there is little information available about the physical aspects of condensation which can lead to ECM and dendrite growth [6]. Another open question is the impact of condensation time on the mean time failure time (MTTF); it can be supposed that the time ratio between condensation time and electrochemical migration time (dendrite growth) is not irrelevant in certain cases. Furthermore, there are also many contradictory statements in the literature. A contradictory statement can be found also about the comparison the ECM behavior of nickel and gold.

The migration ability of gold was first observed on the surface finishes of integrated circuits. On the other hand a numerous other publications have also reported the ECM of gold on ceramic thick film circuits and in ceramic encapsulations as well [7-15]. The studies revealed that the surface ionic impurities, like chloride play an important role in the case of gold migration. While in the chloride ion-free cases migration was not observed. Consequently, the gold migration cannot be attributed to the classical model, since in this case the contamination is not a form of migration modifying factor, but the root cause of migration. According to the first publications essentially $\mathrm{Cl}_{2}$ gas evolution and / or tetrachloro-gold complex ion formation were assumed on the anode $[10,12]$ :

$\mathrm{Au}+4 \mathrm{Cl}^{-} \rightarrow \mathrm{AuCl}_{4}^{-}+3 e^{-}$

However, the formed complex anion in eq(1) leads to a contradiction. The main problem of this model is that the electrochemical process according to Eq. (1) leads to the formation of negative ions, therefore their migration toward the cathode can hardly be imagined. The tetrachloro-gold complex ion might be unstable and further chemical reactions had to be supposed. The main forms of gold in solutions are complex ions of the type [16]: 


$$
\left[\mathrm{Au}(\mathrm{OH})_{x} \mathrm{Cl}_{y}\right]^{(x+y-4)-}, \text { where }(x+y<4)
$$

Among these complexes, positive ions may also be present (for example when $x=y=1$ ), the migration of which toward the cathode is possible.

According to another theoretical explanation [17], the following chemical 'chain reaction' is also possible in acidic media, which is present in the anode region (since the deposition of $\mathrm{OH}^{-}$ions results in an enrichment of $\mathrm{H}^{+}$ions there) [16-17]:

$$
\mathrm{AuCl}_{4}{ }^{-}+\mathrm{H}^{+} \rightarrow \mathrm{H}\left[\mathrm{AuCl}_{4}\right] \rightarrow \mathrm{HCl}+\mathrm{AuCl}_{3} \rightarrow \mathrm{H}^{+}+\mathrm{Au}^{3+}+4 \mathrm{Cl}^{-}
$$

The resulted $\mathrm{Au}^{3+}$ ions are positive metal ions that can migrate toward the cathode and form dendrites similarly to the classical model. Generally, the process of contaminant induced migration can be summarized in the following steps $[5,16]$ :

1) Primary negative complex-ion formation by an anodic corrosion induced by halogen contaminates (see Eq. (1)).

a. A multi-step chemical process resulting in metal ions or secondary complex cations (Eqs.(2) and (3)).

2) Cation migration through the electrolyte under electrical field toward the cathode.

3) Electrochemical deposition at the cathode forming metallic dendrites.

It can be also found such publications that reported about the gold migration without any contaminants. According to Noh at al, gold can follow the classical ECM model [18-19]. Accordingly, so much is certain that gold is prone to migration, but the migration theories and contradictions of gold have to be clarified.

For some other metals many contradictory phenomena were also reported. Such as the anodic dendritic growth of nickel, that was published by many authors [20-24]. However, no publications gave detailed and comprehensive explanation for the anodic dendritic growth phenomenon. Moreover, some researcher tried to explain the ECM behavior of $\mathrm{Ni}$ with the classical migration model $[20,25]$, ignoring the anodic dendritic growth. Finally, some publications reported a satisfactory ECM theoretical background of nickel that was very different model comparing the classical one $[5,26]$. In general, the model of anodic dendrite growth can be summarized in the following steps: 
1) Primary cation formation by an anodic corrosion, a chemical process resulting in secondary anionic complexes.

2) Anion migration through the electrolyte under electrical field toward the anode.

3) Electrochemical-chemical processes at the anode resulting in the deposition of metallic dendrites.

It must be also mentioned the even newer publications reported that nickel follows the classical ECM model [18-19]. So, as it was shown in case of gold, the ECM literature of nickel is also very contradictory. So, the migration theories of nickel have to be also clarified. Therefore, in this study the ECM behavior of $\mathrm{Ni}$, ENIG and $\mathrm{Cu}$ (as reference) was investigated on $\mathrm{NaCl}$ contaminated printed wiring boards (test boards) using a climatic chamber. The climatic chamber simulates the water condensation process as possible way of ECM.

\section{Experimental}

The susceptibility of migration was checked by a Thermal Humidity and Bias (THB) test, called dew point test, with an in-situ optical and real-time electrical measuring platform. The setup of the measuring platform/method was described elsewhere [27]. Optical inspection and the electrical measurement were carried out in the same time. In this case the aim was that the electrical results verify the optical ones.

In order to carry out the dew point tests, a standard comb pattern was designed according to the IPC-B-25-A test board with the following main parameters: the raster of the conductor stripes was $0.4 \mathrm{~mm}$ with a gap size of $0.2 \mathrm{~mm}$ on an FR4 substrate. The interdigital patterns (Fig. 1) were made by conventional photolithography and wet etching processes. The Cu base conductor was coated by $\mathrm{Ni}$ and ENIG. During this study the following samples were investigated:

1) Bare $\mathrm{Cu}$ on $\mathrm{FR} 4$ with and without $\mathrm{NaCl}$ contamination.

2) $\mathrm{Cu}+\mathrm{Ni}$ on $\mathrm{FR} 4$ with and without $\mathrm{NaCl}$ contamination.

3) $\mathrm{Cu}+\mathrm{ENIG}$ on $\mathrm{FR} 4$ with and without $\mathrm{NaCl}$ contamination.

The $\mathrm{NaCl}$ contamination simulates the so called salt spreading effect at the sea side. Therefore, the samples were immersed into a $3.5 \mathrm{wt} \% \mathrm{NaCl}$ solution and dried under normal/natural conditions. During the dew point tests two kind of failure times were measured 
(10 VDC applied as a test voltage): Mean Time To Condensation (MTTC) and Mean Time To Dendrite (MTTD). MTTC is measured between the start of the test and the first presence of a dendrite, and MTTD is measured between the first presence of a dendrite growth and the formed short.

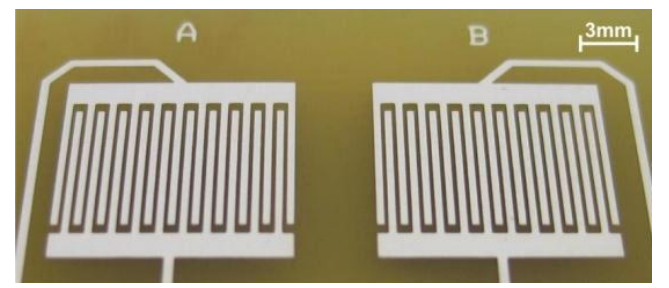

Fig.1. Nickel coated test board for dew point test.

The dendrites and precipitates formed during the process were also investigated by Scanning Electron Microscopy (SEM) in order to study their microstructures and by Energy Dispersive $\mathrm{X}$ - ray Spectroscopy (EDX) to analyse the elemental compositions.

\section{Results of THB test}

Preliminary measurements THB tests were carried out on cleaned $\mathrm{Cu}$ test boards as reference. The aim was to observe the water condensation process and the induced ECM processes without any contaminant presence. The results show, that the mechanism of ECM during dew point test can be divided into minimum three steps (See Fig. 2):

1) Small droplets occurred (nucleation) on the metal surface first (start of MTTC).

2) During nucleation of water droplets, "water-bridges" were formed between the adjacent metal surfaces (end of MTTC and start of MTTD).

3) After the formation of "water-bridge(s)", dendrite growth was observed, which finally resulted in short (end of MTTD).

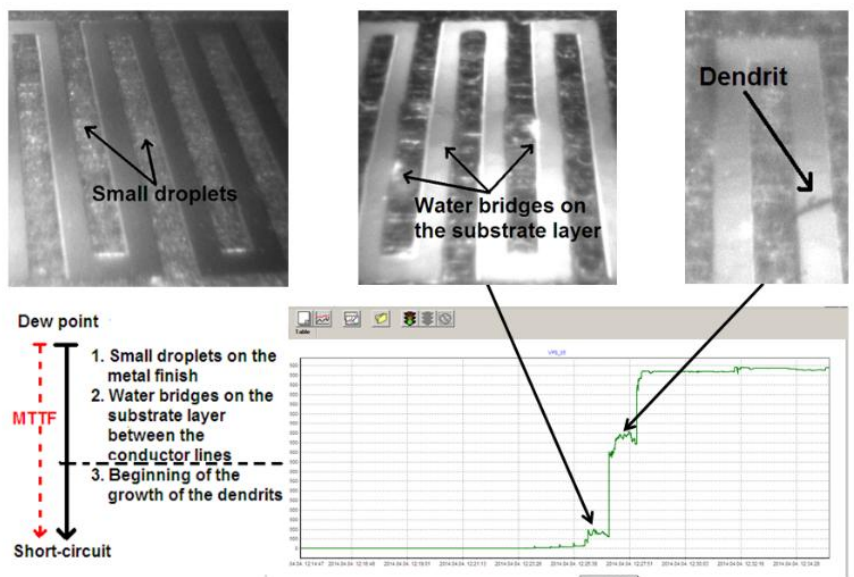

Fig.2. Optical and electrical results of a contaminant free Cu test board during THB test (Left-up: Occurrence of water droplet on the metal surface, Middle-up: "water-bridge" formation, Right-up: Dendrite formation, Leftdown: qualitative model, where MTTF is the mean-time-to-failure (MTTF = MTTC + MTTD), Right-down: electrical results to verify the optical ones). 
Similar results (three steps ECM model) were observed on Ni and ENIG samples during the THB tests. However, the MTTC and MTTD values were different even in case of the contaminated samples (See Fig. 3). According to the MTTF data the highest susceptibility for ECM has the $\mathrm{NaCl}$ contaminated $\mathrm{NiAu}$ sample, while $\mathrm{Cu}$ sample showed the higher resistance against ECM, which was an unexpected result. In order to find out the root causes of the THB results, SEM-EDX methods were carried out combined with optical microscopy (OM).

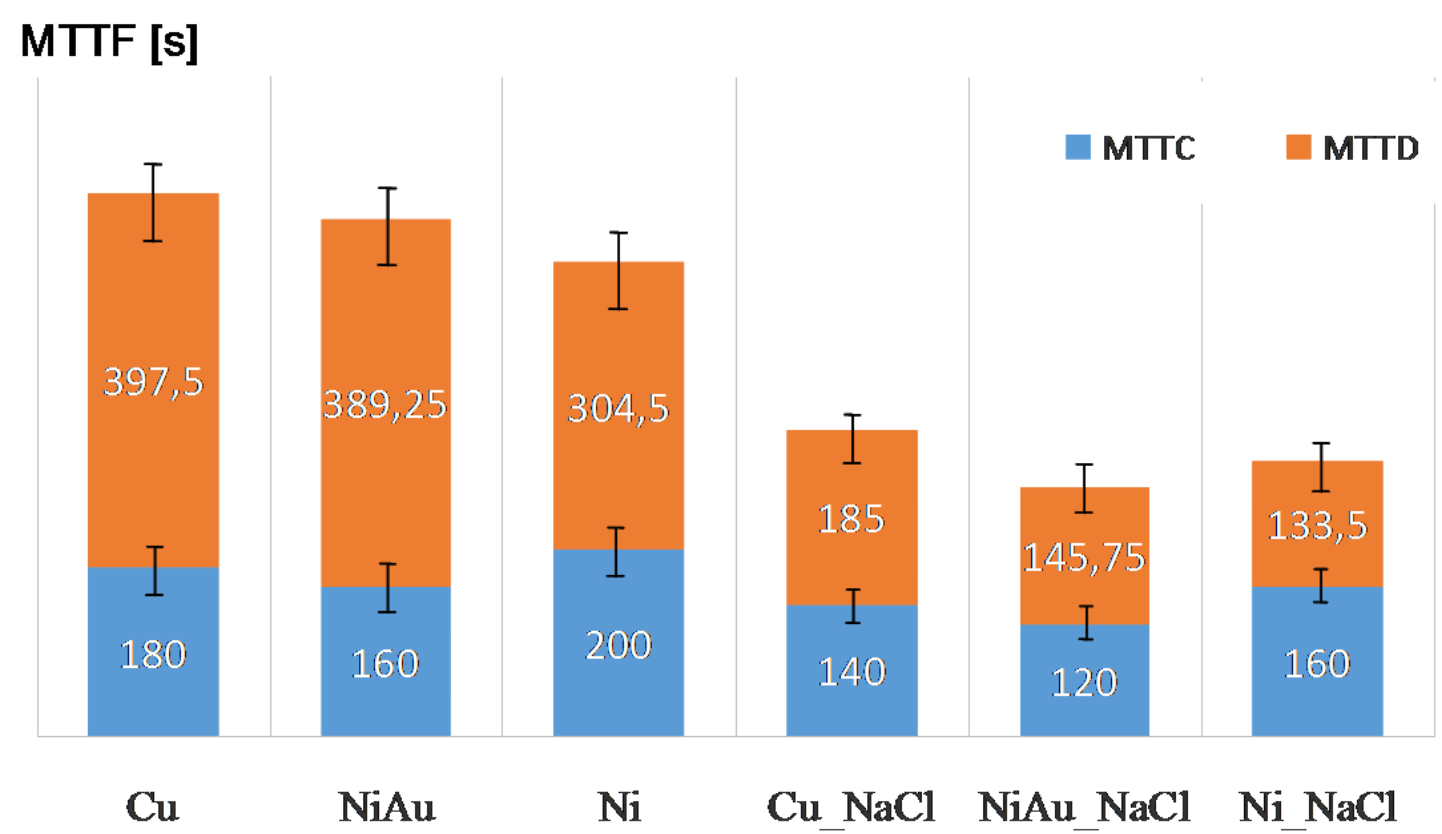

Fig. 3. MTTF average values after THB test in case of cleaned and contaminated samples.

\section{Results of SEM-EDX investigations}

The SEM-EDX results confirmed that $\mathrm{Cu}$ took part during the ECM processes in case of cleaned and $\mathrm{NaCl}$ contaminated $\mathrm{Cu}$ samples as well.

In case of cleaned $\mathrm{NiAu}$ samples $\mathrm{Cu}$ and $\mathrm{Ni}$ have also taken part during the ECM processes (See Fig 4. and Table 1.) Furthermore, no Au element can be detected during the EDX measurements. In case of $\mathrm{NaCl}$ contaminated $\mathrm{NiAu}$ samples similar results were found. Namely, $\mathrm{Cu}$ and $\mathrm{Ni}$ took also part during the ECM processes, while precipitates contain some chlorides (See Fig. 5 and Table 2.).

In the case of cleaned and $\mathrm{NaCl}$ contaminated $\mathrm{Ni}$ samples $\mathrm{Ni}$ and $\mathrm{Cu}$ took also part during the ECM processes. It was very similar result comparing to the NiAu case, hence no $\mathrm{Au}$ was detected only $\mathrm{Cu}$ and $\mathrm{Ni}$ (Fig. 5 and Table 2.). 

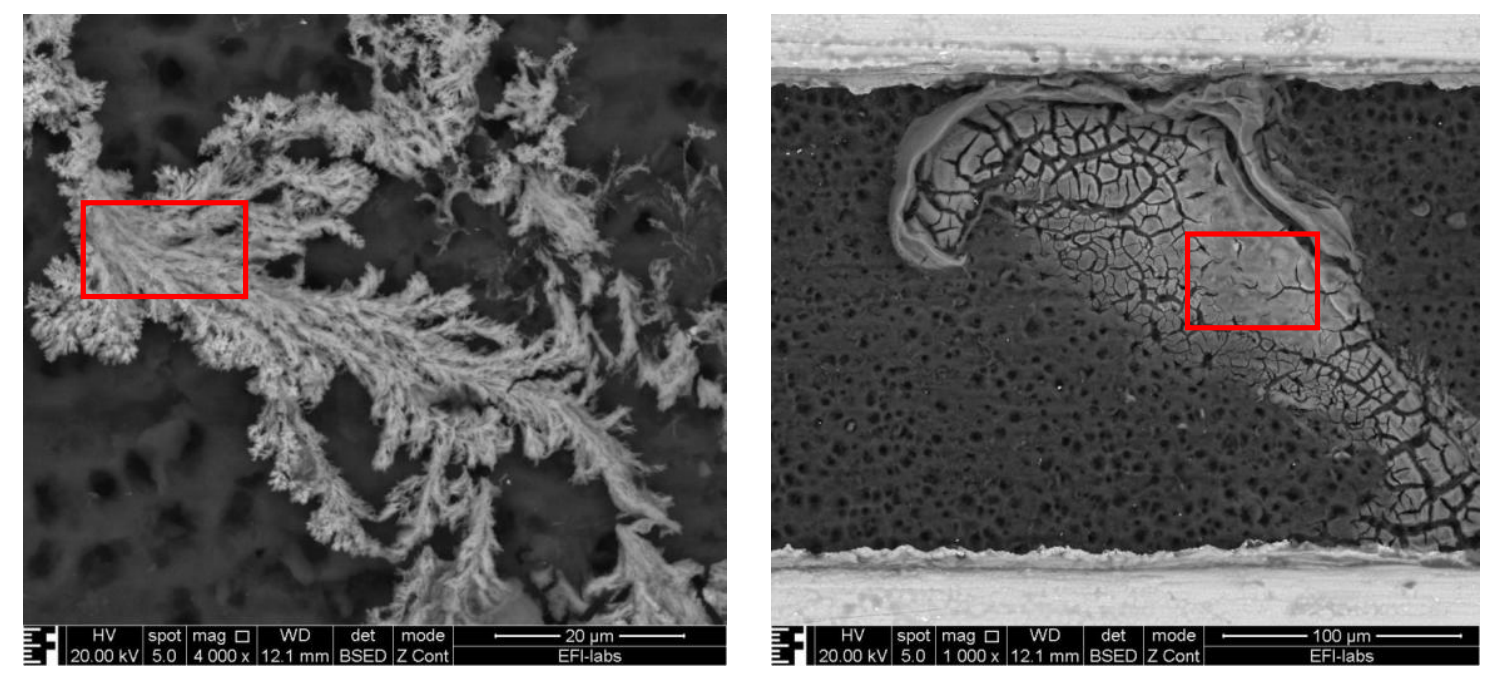

Fig. 4. SEM pictures about the formed dendrites (left) and precipitates (right) in case of NiAu surface finish without $\mathrm{NaCl}$ contaminant.

Table 1. EDX results according to Figure 4 (See red rectangles).

\begin{tabular}{|l|r|r|r|r|r|l|}
\hline Spectrum (at\%) & \multicolumn{1}{c|}{$\mathrm{C}$} & \multicolumn{1}{l|}{$\mathrm{O}$} & \multicolumn{1}{c|}{$\mathrm{P}$} & \multicolumn{1}{c|}{$\mathrm{Ni}$} & \multicolumn{1}{c|}{$\mathrm{Cu}$} & $\mathrm{Au}$ \\
\hline Dendrite & 28 & 41 & 6 & 11 & 14 & 0 \\
\hline Precipitate & 45 & 46 & 0 & 3 & 5 & 0 \\
\hline
\end{tabular}
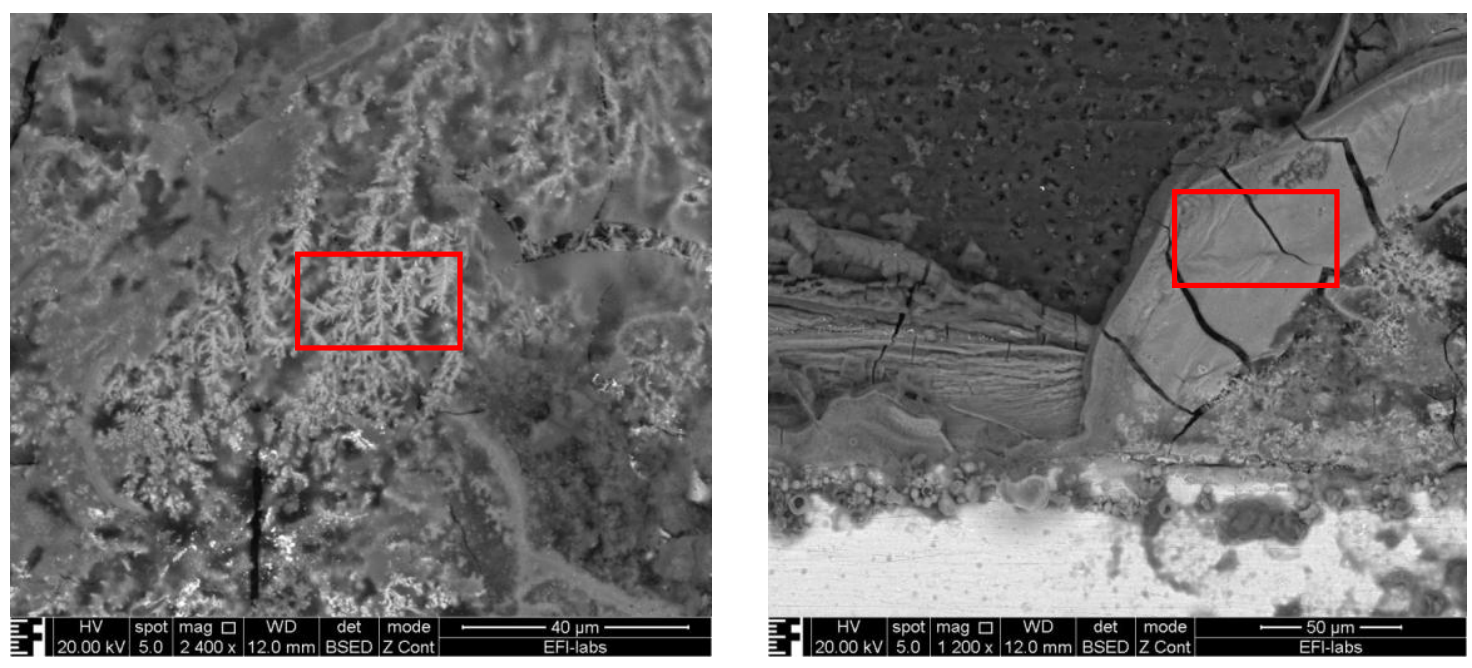

Fig. 5. SEM pictures about the formed dendrites (left) and precipitates (right) in case of NiAu surface finish with $\mathrm{NaCl}$ contaminant.

Table 2. EDX results according to Figure 5 (See red rectangles).

\begin{tabular}{|l|r|r|r|r|r|r|l|}
\hline Spectrum (at\%) & \multicolumn{1}{c|}{$\mathrm{C}$} & \multicolumn{1}{c|}{$\mathrm{O}$} & $\mathrm{Na}$ & \multicolumn{1}{c|}{$\mathrm{Cl}$} & $\mathrm{Ni}$ & $\mathrm{Cu}$ & $\mathrm{Au}$ \\
\hline Dendrite & 30 & 42 & 3 & 3 & 5 & 17 & 0 \\
\hline Precipitate & 32 & 41 & 6 & 7 & 8 & 6 & 0 \\
\hline
\end{tabular}




\section{Discussion}

The ECM processes during THB test was divided into two parts; water condensation process (MTTC) and electrochemical migration (MTTD) including precipitate formation and dendrite growth. Therefore, the two parts (MTTC and MTTD) during THB test will be discussed separately.

The water condensation time was depended mainly on the thermal parameters (e.g.: thermal diffusivity) and the surface roughness differences of the metals. The different surface roughness influences the hygroscopic behaviour. However, in case of surface roughness investigation no significant differences were found.

On the other hand, due to exothermic nature of the water condensation process, the so called thermal diffusivity must be also taken into consideration. The better (bigger) thermal diffusivity can transport more heat if the volumes of the materials are equal, which increases the intensity of the condensation.In the case of thermal diffusivity parameters high differences were found (See Table 3). The MTTC results presented in Figure 3 and the theoritical background based on the Table 3 data are in good agreement. In the case of the $\mathrm{NaCl}$ contaminated samples the same MTTC ranking can be observed (Fig. 3). The relative shorter MTTC times were caused by the $\mathrm{NaCl}$ salt crystals, hence they can act as condensation cores on the surfaces thus can accelerate the water condensation as well.

Table 3. Thermal diffusivity parmeters in case of $\mathrm{Cu}$, Ni and $\mathrm{Au}$ [28].

\begin{tabular}{|c|c|}
\hline & Thermal diffusivity $(\alpha)^{*}$ \\
\hline $\mathrm{Cu}$ & $112.34 \times 10^{-6}$ \\
\hline $\mathrm{Ni}$ & $22.66 \times 10^{-6}$ \\
\hline $\mathrm{Au}$ & $126.9 \times 10^{-6}$ \\
\hline
\end{tabular}

From the MTTD point of view, precipitates and dendrites were formed during the ECM processes.

The precipitates can hinder the ECM processes depending on the type and therefore the different solubility behaviour which has a huge influence on the maximum metal ion accumulation and thus on the probability of the dendrite growth.

According to the EDX results (See Fig 5 and Table 2) and the literature [29], the white color precipitate should be $\mathrm{CuCl}$ in case of $\mathrm{Ni}$ and also in case of $\mathrm{NiAu}$ surface finish. $\mathrm{CuCl}$ has a 
relative higher solubility product constant $\left(K_{s p}=1.72 E-7\right)$ [29]. Furthermore, according to the EDX results and the literature [30], the green color precipitate should be $\mathrm{CuOH}$ in case of pure copper. $\mathrm{CuOH}$ has a low solubility product constant $\left(K_{s p}=2 E-15\right)$ [31]. It means, that the concentration of $\mathrm{Cu}$ ions can decrease in case of $\mathrm{Cu}$ sample, which resulted in higher MTTD values compare to Ni and NiAu surface finishes (See Fig.3).

Another explanation for the MTTD differences is about the dendrite formation during ECM. According to the EDX results the formed dendrites contain $\mathrm{Cu}$ (in case of $\mathrm{Cu}$ samples) and also $\mathrm{Ni}$ (in case of $\mathrm{Ni}$ and $\mathrm{NiAu}$ samples) elements, while no Au was detected (See Table 1, 2). If we observe Figure 3, $\mathrm{Cu}$ showed the highest MTTD value, while Ni showed the lowest and NiAu was in the middle. This can be explained by the very different electrode potentials (Standard Electrode Potential vs. SHE (V)). Nickel has the lowest potential (-0.25 V vs. $\mathrm{SHE}$ ); therefore Ni has got the highest ability for electrochemical oxidation. In case of unloaded condition $\mathrm{Ni}$ and $\mathrm{Au}$ can form a galvanic (corrosion) cell, where $\mathrm{Ni}$ is the anode and $\mathrm{Au}$ is the cathode, therefore $\mathrm{Ni}$ can dissolve and thus $\mathrm{Ni}$ ions were produced, which may take part in the ECM processes as well. Copper has got higher potential $(+0.34 \mathrm{~V})$ compare to $\mathrm{Ni}$, therefore $\mathrm{Cu}$ has less susceptibility for metal ion production, showed longer MTTD (See Fig. 3). Furthermore, the $\mathrm{Au}$ finish hinders the electrochemical oxidation process of $\mathrm{Ni}$ acting as a physical cover layer, thus NiAu showed longer MTTD compare to Ni (Fig. 3).

\section{Conclusions}

The effect of water condensation on ECM was investigated in case of $\mathrm{Cu}, \mathrm{Ni}$ and ENIG on FR4 substrate during a special Thermal Humidity and Bias (THB) test, called dew point test. The results showed that $\mathrm{NaCl}$ crystals can accelerate the condensation intensity and also the migration ability, hence they played role as condensation cores and increased the conductivity of the condensed water. Furthermore, water droplets formed locally "water bridges" between adjacent conductor lines. Finally precipitates and dendrites were formed. The water condensation time (MTTC) also depends on the surface roughness and thermal parameters of the applied conductor and insulation materials, while MTTD mainly depends on the type of electrolyte $(\mathrm{pH})$, on the type of precipitate formation (solubility), and on the type of the used metal finishes (electrode potential) under fixed bias voltage and fixed geometry of the test structures. 
According to the results a qualitative ECM model affected by $\mathrm{NaCl}$ can be summarized as follows in case of Ni and ENIG during THB test:

1) Water condensation process starts (more intense) on the metal and $\mathrm{NaCl}$ crystals played as condensation cores.

2) Formation of "water-bridges" between the conductor lines (start of ECM).

3) Precipitate (probably $\mathrm{CuCl})$ and dendrite $(\mathrm{Cu}$ and $\mathrm{Ni}$ ) formations that resulted in short.

\section{Acknowledgement}

The work reported in this paper was supported by the János Bolyai Research Scholarship of the Hungarian Academy of Sciences. The Author would like to also thank the support for the National Research, Development and Innovation Office - NKFIH, PD 120898. Finally, the Author would like thank to EFI-labs for the SEM-EDX investigations.

\section{References}

[1] V. Verdingovas, M. S. Jellesen and R Ambat, Journal of Electronic Materials, 44, 1116 (2015)

[2] X. Zhong, G. Zhang, Y. Qiu, Z. Chen, X. Guo and C. Fu, Corrosion Science, 66, 14 (2013)

[3] G. Harsányi, IEEE Electron Device Letters, 20, 5 (1999)

[4] X. Zhong, S. Yu, L. Chen, J. Hu, Z. Zhang, Journal of Materials Science: Materials in Electronics, 28, 2279 (2017)

[5] G. Harsányi, IEEE Transactions on Components, Packaging, and Manufacturing Technology-Part A, 18, 602 (1995)

[6] Z. Sheng, M.H. Azarian and M. Pecht, IEEE Transactions on Device and Materials Reliability, 8, 426 (2008)

[7] G. W. Warren, P. Wynblatt and M. Zamanzadeh, Journal of Electronic Materials, 18, 339 (1989)

[8] G. Ripka and G. Harsányi, Electrocomponent Science and Technology, 11, 281 (1985)

[9] A. DerMarderosian, "The Electrochemical Migration of Metals", Proc. of the $11^{\text {th }}$ International Microelectronics Symposium (1978), p. 134

[10] N. L. Sbar, IEEE Transactions on Parts, Hybrids, and Packaging, 12, 76 (1986) 
[11] A. Christou, J. R. Griffith and B.R. Wilkins, IEEE Transactions on Electron Devices, 26, 77 (1979)

[12] F. J. Grunthaner, T. W. Griswold and P. J. Clendening, "Migratory Gold Resistive Shorts: Chemical Aspects of a Failure Mechanism", Proc. of the $13^{\text {th }}$ IEEE International Reliability Physics Symposium, (1975), p. 99

[13] J. Wright, "Reliability Improvements of Plastic Semiconductors Using Gold Metalization", Proc. of the $11^{\text {th }}$ IEEE International Reliability Physics Symposium, (1973), p. 224

[14] A. Shumka and R. R. Piety, "Migrated-Gold Resistive Shorts in Microcircuits", Proc. of the $13^{\text {th }}$ IEEE International Reliability Physics Symposium, (1975), p. 93

[15] E. B. Hakim and I. R. Shappiro, Solid State Technology, 4, 66 (1975)

[16] G. Harsányi, Microelectronics Reliability, 39, 1407 (1999)

[17] J. M. Gaur and G. M. Schmid, Electroanalytical Chemistry and Interfacial Electrochemistry, 24, 279 (1970)

[18] B. I. Noh, J. B. Lee and S. B. Jung, Microelectronics Reliability, 48, 652 (2008)

[19] B. I. Noh, J. W. Yoon, W.S. Hong and S.B. Jung, Journal of Electronic Materials, 38, 902 (2009)

[20] M. Kohara, Y. Mashiko, K. Nakazaki and M. Nunoshita, "Mechanism of Electromigration in Ceramic Package Induced by Chip-Coating Polyomide", Proc. of the 40 th IEEE Electronic Components Conference, (1990), p. 894

[21] L. C. Matthew and D. L. Rath, "The Waterdrop Test - Highly Accelerated Migration Testing", Materials Developments in Microelectronic Packaging Conference Proceedings, (1991), p. 353

[22] T. Kawanobe and K. Otsuka, "Metal Migration in Electronic Components", Proc. of the 32nd $I E E E$ Electronic Components Conference, (1982), p. 220

[23] P. Dumoulin, J. P. Seurin and Marce, "Metal Migrations Outside the Package During Accelerated Life Tests", Proc. of the 32nd IEEE Electronic Components Conference, (1982), p. 98

[24] D. D. Chang, J. A. Fulton, H. C. Ling, M. B. Schmidt, R. E. Sinitski and C. P. Wong, “Accelerated Life Test of Z-Axis Conductive Adhesives”, IEEE International Reliability Physics Symposium, (1993), p. 211

[25] B. Rudra, M. Li, M. Pecht and D. Jennings, Circuit World, 22, 67 (1995) 
[26] G. Harsányi, "Material Design Aspects of High Reliability, High Density Interconnects", Proc. of the Int. Conf. on Electronic Materials, Hsinchu, Taiwan, (1994), p. 225

[27] B. Medgyes, B. Illés, R. Berényi and G. Harsányi, Journal of Materials Science: Materials in Electronics, 22, 694 (2011)

[28] Y.S. Touloukian, R.W. Powell, C.Y. Ho, M.C. Nicolaou, Thermophysical Properties of Matter-The TPRC Data Series. Volume 10. Thermal Diffusivity, 1st edn, (IFI/PLENUM, New York-Washinton 1974), pp. 35-36.

[29] D. R. Lide, Handbook of Chemistry and Physics, 90th edn, (CRC Press: Taylor and Francis Group, 2009), pp. 8-127.

[30] A.G. Massey, N.R. Thompson, B.F.G. Johnson, R. Davis, The Chemistry of Copper, Silver and Gold, 2nd edn. (Pergamon Press, New York, 1975), pp. 28-29.

[31] D. Starosvetsky, N. Sezin, E. Abelev, T. Cohen-Hyams, Y. Ein-Eli, J. Electrochem. Soc. 161, C77 (2014) 